\title{
EDUCATIONAL
}

TECHNOLOGY

\section{Television in higher education - past, present and future}

\author{
Andrew Greig \\ Television Service \\ University of Sydney
}

\begin{abstract}
A light hearted look at the role of television in higher education and the problems facing practitioners in this field.
\end{abstract}

A few years ago you could take a group of visitors into the College Television Studio and keep them happily amused for hours just "seeing themselves on the box". You could always guarantee a giggle from a "speeded up" movie ("How to use A Chemical Balance" at Charlie Chaplin speed). No longer - everyone knows about video.

The very box itself - the cathode ray tube - has spawned and swarmed out of the home. It has invaded offices and railway stations, stock exchanges and amusement arcades. I'm using one at this very moment as I write this on our Mac. Even University Academics agree that a Television Screen can now (sometimes) be a source of useful information. It's no longer always a signal to switch off and relax. You could almost say that the Box has become respectable.

\section{Have attitudes changed?}

But what about educational television? I was recently looking at the 1977 issue of the ASET Yearbook (AJET's predecessor). In it, Dr Deane Hutton writes on "Ten Years in Educational Television" - looking back to times almost twenty years from today. Hutton discusses: the uses of television, the continuing triviality of much broadcast television, the best styles for presentation, the concern over children's viewing habits and the need for research. One section is entitled "Education and Television: impossible marriage?" La plus ca change... 


\section{University Television - The Past}

Television was introduced into Australian Universities in the early sixties. It was originally seen as a useful tool for dealing with a massive expansion in Science teaching and a shortage of qualified lecturers (things have changed since then!) Lectures were beamed live, on 'closed circuit television', to various overflow theatres around the campus or recorded and then repeated.

The motives were worthy and the idea probably worked reasonably well in the circumstances but as expansion slowed down and the shortage of lecturers eased the 'televised lecture' came under fire. Students objected to boring 'talking head lectures whilst the academics found that good programs took a good deal of effort to prepare. Consciously or not they probably also perceived television as being a possible threat to their jobs. The 'Television Lecture', in my opinion, gained an unjustly bad reputation (We still run them successfully at the University of Sydney, but that's another story.)

However: other applications were emerging. For example 'video', as it was becoming known, was found very effective in demonstrating surgical and laboratory techniques, in showing case histories and for simulating interactions with 'clients. There was much experimentation with the technology of television - for showing close-up views of specimens or for recording behavioural phenomena.

The presence of a television studio on campus often focused interest on the use of audio-visual methods and on educational technology in general. Sometimes it even led to Staff Development activities. In some cases the Library muscled in on the act (Information Science!) and in some institutions the School of Communications made a takeover bid, almost inevitably at the expense of any serious educational production. The equipment became lighter. cheaper and more reliable. In contrast to the most developed nations. Australia made very few efforts to use broadcast television in adult and higher education.

\section{The Present}

Right now we are in the age of the Squeeze. Everyone in tertiary institutions is suffering, but when (quite literally) the chips are down, new television cameras can look less essential than the vacant Senior Lectureship in Computer Science. Educational Technologists could be very helpful in these difficult times but they do not yet hold political power in our tertiary institutions. 
In the United Kingdom where central AV Units have been vulnerable for rather longer, various solutions have emerged. They can be summarised as "Charge More, Earn More and Make Yourself Indispensable to the College's Public Relations". Visiting the United Kingdom a few weeks ago (July 1986), I found that the big television centres at Manchester and Leeds Universities now provide a good proportion of their budgets by earnings from commercially oriented production.

\section{The Future}

As we have seen, Television/Video is no longer the arcane science that it used to be. There is a danger here for professional educational television producers that this familiarity may breed contempt for their skills (particularly when funds are tight). I think however that it is more likely that the omnipresence of video will lead to a greater demand in the long run for centres of expertise on the campus. If nothing else, the increasing pervasiveness of "The Media" will make academics realise that they need some media people on their own side. Hopefully Australia will open up at least one national educational broadcast channel and make real use of the satellite for education.

'Convergence' will be the trend in several areas. "Solid state" cameras (CCD), digital recorders and other advances will lead to a convergence of 'Broadcast' and 'Educational' standards in television. Broadcast radio studios on campus are already commonplace. 'Desktop Publishing' is demonstrating a similar trend in the area of Print.

Evident for some years has been the convergence of computing and video technologies. The result of this is that the storage, retrieval, manipulation and transmission of visual material will all soon be profoundly facilitated. In more simple language, it is quite feasible that in a few years a University library (or media centre) could house every relevant educational videotape/film ever made (and probably not a few irrelevant ones as well). Any one of these videotapes, indeed any single frame of one, could be accessed within a few seconds and transmitted to any portion of a campus to the PC (or whatever it will be called) in the lecturer's office, to a student room or to the giant flat screen in one of the lecture theatres.

"Will there still be lecture theatres?" you ask. Well, take my word for it, we shall always have them as long as human beings like to meet together. And yes, for the same reason, there will still be campuses (camp)?) and (I think) that there will still be the 'warmware' (lecturers) but I don't know how many.

What then will be the role of television? Obviously the medium of (educational) television is changing its nature all the time. In the early 
days it used to be simply 'moving pictures at a distance'. Now it might be better described as 'electronic images - live or stored/lifelike or symbolic/still or moving'. That gives us an immense amount to play with in education.

Certainly there will be the continuing debates on such issues as:

- Mass Instruction versus Individualised Learning.

- Distance versus campus education.

- The role of the 'Lecturer'.

- What standard of production?

- Exchange and sharing of resources.

- Broadcast or cable? (i.e. public or private?)

- Regional or central facilities?

- Who runs the show?

Let us assume then, that the community has come to its senses and that Higher Education will be run a little more efficiently and effectively than it is at present. Let us then take our group of visitors to the College VidCentre in the year 2007.

Well, first of all they won't actually come there in person. They will take their tour at a distance over satellite or on fibre optic cable from their various homes and places of work. We will show them by instant access "the year's feature films in one minute" end let them experience the "Be a Brain Surgeon" laser simulator. They can down load it into their "Home Education Centres" for later experimentation. We will of course arrange a simultaneous live hook up between Lunar College and Bond University and show them our own college library containing the sum of human knowledge in Micro storage. (It is about the size of a large filing cabinet.)

With luck, we may keep them happily amused for a few minutes.

\section{Reference}

Hutton, D.W. (1977). Ten Years in Educational Television. ASET Yearbook, 1.

Please cite as: Greig, A. (1986). Television in higher education - past, present and future. Australian Journal of Educational Technology, 2(1), 29-32. http: / / www.ascilite.org.au/ajet/ajet2/greig.html 